Special issue call for papers from Information and Learning Science

http://www.emeraldgrouppublishing.com/products/journals/call for papers.htm?id=7836

\title{
Digital Literacies: Preparing pupils and students for Their information journey in the $21^{\text {st }}$ century
}

\begin{abstract}
In a fast-moving world where technology has become intertwined with our daily lives, meaning information is available at our fingertips, information overload (Khabsa and Giles, 2014 ) is just one of many challenges that this technological overhaul has presented.

Drawing on key literature in the fields of education and academia and adopting the analogy of a journey to represent lifelong learning, this bipartite paper explores how both primary school pupils and university students are required to access information in their very own information journeys in this 'Information Age'. The similarities and differences between child and adult learners are considered.
\end{abstract}

This article shares practical strategies for promoting the smarter use of information- and a shorter journey- for these 'travellers' along the way. This article essentially aims to raise questions in the minds of educators as they help to prepare their learners to learn.

Key words: information, lifelong learning, digital literacies, information overload

\section{Introduction}

In a fast-moving world where technology has become intertwined with our daily lives, meaning information is available at our fingertips. Information overload (Khabsa and Giles, 2014 ) is just one of many challenges that this technological overhaul has presented. In the realms of education, becoming a confident navigator of information is key to successful lifelong learning; we are living in the 'Information Age', also referred to as the 'Computer Age', 'Digital Age', or the 'New Media Age'. Humanity is evolving. Essentially, this era is an era based on information, and the acquisition and ownership of information is a defining trait of this age. This article shares practical strategies for promoting the smarter use of information- and a shorter journey- for these 'travellers' along the way.

But what exactly is information? The answer to this at-first simple question is hard to define. If knowledge is that state of knowing, can information be the measurable unit? Janich (2018) argues that 'our understanding of information is based in the much broader history of 
scientific naturalism', essentially that 'science is a fundamental aspect of the world and not a human contrivance' (Janich, 2018: 16). Many interpretivists, however, would argue that information can mean different things to different people, and that individuals interact with information in a range of ways that are founded in behaviour, and the social world, rather than that of the positivist, scientific world. The definition of 'information' assumed for this article is that information is an entity that gives fact or knowledge to the consumer, in any field and for any purpose.

Another definition that must be established here is that of 'digital literacy'. Gilster coined the term 'digital literacy' in 1997 as 'the ability to both understand and use digitized information' (Gilster 1997:2). Digital literacy, therefore, refers to the variety of literacies associated with the use of innovative technologies (Mohammadyari \& Singh, 2015). As Hockly (2012) highlights:

'Literacy has always been a primary goal of education, but the constantly evolving digital landscape means that new skills and literacies are required' (Hockly, 2012: 108).

These new 'skills and literacies' that Hockly refers to can be gathered under the overarching term of 'digital literacies'. As a verb, digital literacy is a fundamental life skill in today's knowledge economy and information society (Bawden, 2001). Digital literacy constitutes new practices rather than new instances of established practices (Simpson \& Obdalova, 2014). Proficiency in digital literacy refers to the ability to read and write using online sources and includes the ability to select sources relevant to the task, synthesize information into a coherent message, and communicate the message with an audience (Bulger, Mayer, \& Metzger, 2014). Appel (2012) defined digital literacy as the ability to find and analyse information by using computers.

Regardless of the definitions chosen for both 'information' and 'digital literacy', one inarguable point is that the information explosion has changed the way in which individuals acquire and control information, presenting challenges and opportunities for the information traveler. This bipartite paper considers the lifelong learning experience, exploring hot both primary school pupils and university students are required to access information in their very own information journeys in this 'Information Age'. The similarities and differences between child and adult learners will be considered. 
This article will also share practical strategies for promoting the smarter use of informationand a shorter journey- for these 'travellers' along the way. The article argues that to travel a successful information journey in our Information Age, digital literacy- and competency with the devices used to access this digital literacy, such as mobile devices or laptops- must be mastered.

\section{How modern technologies change the experience}

The information journey takes us from print, to the realm digital information 'and beyond' (Yousuf Ali, 2016:67). We need to deal with information as we encounter it along the journey, but how we interact with information at different touchpoints is a significant aspect of the information journey. By considering how we interact with information, it is only then we can review how to make these interactions more purposeful, more enjoyable and more efficient.

The encouragement of digital literacy and Information Communication Technology (ICT) competency is essential for a more effective information journey, drawing upon online sources such as websites, e-journals and other e-resources. Encouraging digital literacy and ICT competency has the potential to enhance organizational performance and achieve strategic goals in the information age (Kasemsap, 2018: 2253)

But what exactly is the information journey and how does it overlap with our journeys of lifelong learning? Findings by Ibekwe-SanJuan (2017) revealed six recurring themes that portray a journey of information, from its most basic manifestation as bits of data to its more complex and societal functions. The study tended to show that intellectual or academic factors outweigh cultural, linguistic or geographic ones in the students' conceptions of information. This would indicate the importance of the domain over linguistic or geographic factors in their conceptions of information (lbekwe-SanJuan, 2017: 1).

\section{Children: starting the information journey}

Literacy practices for children are constantly developing and this means that the implications for how they deal with the influx of digital information that they receive are far reaching (Burnett, 2016). Digital devices are part of everyday life for many children and can be some of their earliest literacy experiences. Young children are engaged in a variety of multimodal, multimedia practices from an early age and it is imperative that educators help them to manage the amount of information they receive and how they portray themselves online. Many texts that they encounter are from outside of school or family and are often formed around popular or consumer culture. Their engagement with these electronic texts can allow them to outmanoeuvre or subvert the instructions of adults (Carrington, 2005). 
Marsh et al (2005) and Marsh (2010) argue that children's learning in digital technology is scaffolded both implicitly and explicitly by their parents and other family members. As a result, their competence in the use of mobile phones and tablets is established from an early age. With this 'mobile literacy', they are able to create and distribute texts with ease as their observations of adults around them demonstrate that this is a legitimate social practice this allows them to produce and receive information in their own right and therefore become active in global flows of information.

The exposure that children have to new technology allows them access to a greater range of texts and they quickly develop skills to navigate internet sites and other forms of communication technologies. A possible problem with this is that the multimedia practices of children at home are growing more rapidly than they are in school (Arrow and Finch, 2013). The changes that have occurred in technology has meant that everyday practices in reading and writing have changed which means that children today can construct texts in multiple modes and media and move easily from one mode to another (Kervin and Mantei, 2016; Arrow and Finch, 2013). Although traditional texts are considered as multimodal as they contain a variety of drawings, photos and diagrams, changes in digital technology have expanded the reading material that children engage with which has meant that the skills they need to read such texts have changed. Screen based texts are "complex multimodal ensembles of image, sound, animated movement" (Jewitt, 2005: 316) and children need to be able to engage meaningfully with them. Burnett et al (2014:162) feel that "It is important that they are able to be equipped to select, critique and use different modes and media and use them creatively, persuasively and for different purposes".

With the onset of and increased focus on 'fake news' it is important that children develop the skills to critically examine digital texts, the children's commissioner for England has emphasised that the curriculum needs to prepare children for the skills they will need in the digital world (Picton and Teravainen, 2017) and critical digital literacy may be able to offer such skills. Critical literacy encourages children to question and challenge the relationships between language and social practices that advantage some groups and disadvantage others. "Critical literacy practitioners accept that language and the way we use language to read, write, view, speak and listen is never neutral or value free" (Knobel and Healy 1998, p8). Within this practice children are encouraged to analyse and evaluate the texts that they use, recognising that they may not be neutral and value free. 
As discussed earlier the skills that children need to navigate their way through digital texts are changing and they need very specific skills to engage with them. As multimodal texts can be read in a variety of ways, appear differently on different applications and may change rapidly within a minute the interactions that children have are more complex. Burnett and Merchant (2012: 45) argue that a "more nuanced understanding of the relationships between texts, audiences, information and power has emerged" as it is harder to identify positionality and ideology in digital texts as they are more fluid. This can make the consideration of digital texts problematic for children.

When working with the wealth of information that is found online children need the opportunity to develop the skills to make connections between what is going on in the world and their own lives. Teachers can help them by considering what children need to know and where they can find the information; added to this, children should have the time to discuss texts to examine design choice and why the authors have made the choices they have. Within the times of fake news there also needs to be a consideration of who benefits from the texts and who are disadvantaged by them. Such an approach could include activities to explore the power relations that are apparent within and around texts taking consideration of the economic and cultural forces that act upon print based and digital texts (Dowdall, 2009).

Burnett and Marchant (2011), whilst acknowledging that critical literacy within digital texts may be problematic, put forward a model to demonstrate that it may be possible within the primary classroom. Their model has 3 notions: practice; networks, and identity. 'Practice' focusses on what children do in new environments they feel that critical practice is more about a consideration and evaluation of what we and others do on and off-line rather than a consideration of digital technology. Burnett and Merchant (2011: 51) feel that new media are characterised by:

- A tendency to re-mix or re-work existing material

- Alternative connections with known and unknown others

- Opportunities for multiple presentations of the self

- Multimodality and an emergent modularized design

- Blurring of the distinction between consumption/production or reading/writing

Analysing practice may help children to explore their meaning making and their online relationships leading to a consideration of what can be achieved on social media. Networks considers the connections between individuals in the contexts that they take place, this moves away from the consideration on specific texts and may include who children 
communicate with online. Teachers in primary school could use this as a way to consider which communities children could make connections with. Within identity children can explore who it is possible to be in different contexts and how they can establish their online identity. The authors feel that these practices would help children to be empowered through their participation with others.

\section{Students: continuing the information journey}

For students in Higher Education (HE), the information journey has significantly evolved over recent decades. Technology has transformed learning at the postsecondary level and significantly increased the prevalence of digital learning environments (Sharp, 2018: 153). Students in HE need to take ownership of their search for information in their chosen academic field and will need to spend considerable time searching for information, discovering research, and making sense of the literature in a particular area (EMIDIRS, 2012: 38). For students, there is now the dilemma of finding what they need, versus needing what they find. HE institutions should help to support students with shortening the duration length of their information journeys, as well as more efficient strategies for operation. One possible solution here is that of the contested 'open access journals' and open education resources.

What are the potential benefits, therefore, of digital literacies? Students who develop digital literacies as an integral part of their learning are more effective in their study and more employable on graduation - over $90 \%$ of new graduate jobs require digital capabilities (Jisc, 2012). Digitally fluent staff can blend many implement innovative pedagogical practice such as flipped learning, digital curation, and m-learning techniques, and use open educational resources (OEDs) to their maximum benefit. These practitioners enhance the institutional value of digital strategies such as 'Bring Your Own Device' (BYOD) and act as change agents in influencing and driving these strategies forwards.

So what skills exactly are involved in becoming a successful navigator of digital literacies? Several ways of unpicking these skills exist; Pegrum (2011; Dudeney, Hockly, and Pegrum 2012) list four overlapping skill sets corresponding to four fundamental areas (Hockly, 2012):

1 language

2 information

3 connections

4 (re-)design. 


\section{Students and language}

Pegrum (2011) emphasises that language-based literacy is an umbrella term for several other skills, including 'texting literacy'- the ability to decode abbreviated words in text form, and 'hypertext literacy', the skill of navigating online text that uses hyperlinks to link to other online areas. 'Hypertext literacy' is a key part of using a VLE, where, on a weekly if not daily basis, students need to access module pages, find readings recommended by tutors, upload electronic assignment submissions, and interact with peers in wiki spaces.

Perhaps the other key language-based literacy linked to the students' information journey is that of 'mobile literacy', the skills required to manipulate and use mobile or handheld devices (Hockly, 2012). HE classrooms are integrating student voting tools such as 'Mentimeter', 'Kahoot' and 'Quizlet' which can improve student engagement and generate simple student feedback through simple multiple-choice presentations, but in order for students to take part, they need the initial 'mobile literacy' skills. It is ignorant to assume that students in our HE institutions are all 'digital natives' or 'digital immigrants' (Prensky, 2001), and tutors must be confident in their own digital literacy skills in order to disseminate knowledge and skills as necessary.

\section{Students and information}

When it comes to information literacies, there are several skills that students will require to avoid being saturated by information overload. These include 'search literacy' (the ability to search effectively for information online), 'tagging literacy' (labelling or tagging online materials so they are findable), 'information literacy' (being able to critically evaluate sources and information), 'filtering literacy' (knowing how to manage information overload), and 'attention literacy' (knowing when to switch off as well as on) (Hockly, 2012).

Students need to learn how to manage their information journey, including whether to store details of the research they find electronically or in a paper-based system, how to keep track of latest information that they find during their search, and how to keep track of the information they already have (EMIDIRS, 2012: 38).

It is worth consideration how HE institutions can play their part in students' information journey, and one strategy is to provide Information Literacy Strategies. One example of this is how an Information Literacy Strategy (ILS) was brought in to La Trobe University, Australia (Salisbury and Sheridan, 2011). Through participation in a university-wide process of curriculum review and renewal, the library developed a systemic, coherent and sustainable approach to the design of undergraduate information literacy programs. The resulting strategy employs a combination of online and individual instruction and support embedded into the curricula structure and reflected in assessment tasks. It provides a model of 
research skills education that gives all La Trobe University students the opportunity to develop foundation information literacy in first year and to graduate with the necessary information literacy skills for study, work and lifelong learning (Salisbury and Sheridan, 2011)

\section{Students and connections}

These include knowing how to manage your digital identity or online persona ('personal literacy') and 'network literacy', which helps you filter information received from your online networks while you yourself become a node in these networks by passing on relevant information or news (see also Pegrum 2010). 'Participatory literacy' involves being able to create and produce digital content; this in turn includes 'cultural/intercultural literacy' when working with international virtual teams. Students need to be aware of how to manage their 'personal literacy', their digital identity, as they may have profiles on their institutions VLE, or perhaps set up professional social networking pages such as 'Linkedln'. Students also need to develop 'network literacy', which involves the skill of filtering information that is sent through their online networks, judging the validity or importance of such information, and then passing on the relevant parts to other users along the network (Pegrum, 2010). A third skill involved in connection-based literacies is that of 'participatory literacy', where students can make and share digital content, often with peers or tutors through activities such as group presentations as part of a module. This adds another layer to the instructional learning that must take place when students join an HE institution; induction training must provide clear tutorials of the online spaces, the Learning Platforms (LP) or Virtual Learning Environment (VLE) that the institution employs. Findings by Sharp (2018) displayed that the use of collaborative digital literacy practices can be a highly effective method for establishing levels of confidence amongst adult learners when interacting with a VLE.

\section{Students and the skill of re-design}

As Hockly summarises, the skill of re-designing consists primarily of 'remix literacy', a 'macro literacy which includes the ability to recreate and re-purpose already-made digital content in innovative ways' (Hockly, 2012: 120). This essentially involves helping students to develop abilities in finding new ways to carry out tasks with new tools- an important skill in the everchanging face of technology. As Bawden (2008) warns, however, we must appreciate that digital literacies are a 'state' or 'condition' that inevitably will shape and shift over time as modern technologies evolve. As new technologies are employed, new skills must be mastered to accommodate these innovations.

When mental health in university students is at unprecedented levels of crisis (REF), institutions must consider how these adult learners can be encouraged and supported to work 'smarter' not 'harder' on their information journey. Findings show that for staff to 
support students, the staff must have the digital literacy skills required, and barriers to the development of staff digital capabilities include institutional and departmental culture, lack of money, lack of strategy and lack of commitment (UCISA 2014). Concerns over 'digital wellbeing' (the saturation of the teaching and learning environment with digital technologies) have also been expressed (Jisc 2015).

\section{Conclusion}

Regardless of whether a learner is a child in their first years of statutory primary education, or an adult learner embarking on a degree programme or course in Higher Education, educators must see it as part of their role not only to inspire and teach, but also to equip learners with the autonomy to navigate their own quests for information. Critical reading and writing are key, and with the blossom of digital resources, critique of a source is also essential. Essentially, good information flow is stimulated by appropriate organizational culture (Westrum, 2014) and, in turn, information flow is also a useful indicator of the organization's functioning. The primary school setting must prepare pupils to be enquiryminded researchers. At HE level, institutions must refine clunky, front-end Learning Platforms (LP) and ensure that new tools are trialled and adopted where necessary in order to support students' 'mobile literacy'.

To summarise, in order to shorten the information journey and lighten the burden of being an information seeker in this 'New Media Age', whether at a primary or HE level, we need to develop skills that help searches to be precise, concise and targeted. As educators, we need to appreciate that learners come to learn with a range of skills, and we need to assess and develop those skills. We need to promote digital literacy and the associated skills so learners can move easily from one mode to another, from the actual world to the virtual, (Kervin and Mantei, 2016; Arrow and Finch, 2013) to best allow for successful navigation of their digitally-intertwined futures. 


\section{BIOGRAPHICAL NOTES}

Poppy Gibson is a lecturer in Primary Education in the Teacher Education Department., coming into HE after over a decade working in several London primary schools. Poppy currently works on the University of Greenwich's Accelerated degree programme in Primary Education, and is the Modern Foreign Language coordinator, teaching MFL on the PGCE and BA QTS programmes. Key research interests include identity, motivation, and the integration of technology into our lives.

Sarah Smith is a Principal Lecturer and Programme Leader for Primary Initial Teacher Education at the University of Greenwich. Sarah worked in a number of primary schools both in the UK and New Zealand before joining the university in 2007, as Senior Lecturer for English and Literacy. Sarah has responsibility for planning, teaching and evaluating English and Literacy courses for both undergraduate and postgraduate programmes. As Programme Leader for Primary Initial Teacher Education leads the PGCE in Primary Education and the BA in Primary Education with QTS. Her key areas of interest are the use of film in writing, the teaching of poetry, and children's perceptions of what writing is. Her key areas of interest are the use of film in writing, the teaching of poetry, and children's perceptions of what writing is.

\section{REFERENCES}

Arrow, A and Finch, T. (2013) Multimedia literacy practices in beginning classrooms and at home: the differences in practices and beliefs. Literacy 47 (3) p. 131- 14

Bawden D. Lankshear C, Knobel M. (2008) 'Origins and concepts of digital literacy', Digital Literacies: Concepts, Policies and Practices, New York, NY Peter Lang

Belshaw D. (2011) 'What is digital literacy? A pragmatic investigation', $2011 \mathrm{EdD}$ thesis, Durham University. Available at http://neverendingthesis.com (accessed on 18 July 2011)

Burnett, C. (2016) The Digital Age and its Implications for Learning and Teaching in the Primary School: A report for the Cambridge Primary Review Trust. CPRT supported by 
Pearson. Available on: http://cprtrust.org.uk/wp-content/uploads/2016/07/Burnett-report20160720.pdf

Burnett, $C$ and Merchant, $G$ (2011) Is there a space for critical literacy in the context of social media? English Teaching: Practice and Critique, 10 (1) p. 41-57

Calvert, SL (1999) Children's Journeys through the Information Age, New York, NY, US: McGraw-Hill, PsycINFO, EBSCOhost, viewed 27 June 2018.

Carrington, V. (2005) New Textual Landscapes, Information and Early Literacy in J. Marsh ed. Popular Culture, New Media and Digital Literacy in Early Childhood. London:

RoutledgeFalmer. p. 13-27.

Crawford, J, \& Irving, C (2009), 'Our information literacy journey', ALISS Quarterly, 4, 3, pp. 35-37, Library, Information Science \& Technology Abstracts, EBSCOhost, viewed 27 June 2018

Davies A, Fidler D, Gorbis M. (2011) Future Work Skills 2020 , 2011Palo Alto, CA University of Phoenix Research Institute Available at http://tinyurl.com/3m6cpc9 (accessed on 18 July 2011)

Dowdall, C. (2009) Masters and critics: children as producers of online digital texts, in V. Carrington and M. Robinson (eds.) Digital Literacies: Social Learning and Classroom Practices. London: SAGE. p. 43-62.

Dezuanni, M (2018), 'Minecraft and children's digital making: Implications for media literacy education', Learning, Media and Technology, PsycINFO, EBSCOhost, viewed 15 June 2018.

Dudeney G, Hockly N, Pegrum M. (2012) Digital Literacies. Harlow: Pearson

EMIDIRS (2012) 'The joy of information. Part 3: managing your information journey' 2012, Essentially MIDIRS, 3, 8, pp. 38-43, CINAHL Plus with Full Text, EBSCOhost, viewed 27 June 2018.

Gilster, P. (1997) Digital Literacy. New York: Wiley Computer Publishing. 
Hockly, N (2012) Digital literacies, ELT Journal, Volume 66, Issue 1, 1 January 2012, Pages 108-112, https://doi-org.oxfordbrookes.idm.oclc.org/10.1093/elt/ccr077

lbekwe-SanJuan, F (2017), 'The journey of information. How students perceive information in France using the draw and write technique', Information Research, 22, 1, pp. 1-14, Library, Information Science \& Technology Abstracts, EBSCOhost, viewed 27 June 2018.

Janich, P. \& Hayot, E. \& Pao, L. (2018). What Is Information? Minneapolis: University of Minnesota Press. Retrieved June 27, 2018, from Project MUSE database. Available at: https://muse.jhu.edu/ (accessed June 27, 2018)

Jewitt, C. (2005) Multimodality, "Reading", and "Writing" for the $21^{\text {st }}$ Century. Discourse: studies in the cultural politics of education. 26 (3) p.315-331.

Jia Tina, D (2014), 'The Information Journey of Marketing Professionals: Incorporating Work Task-Driven Information Seeking, Information Judgments, Information Use, and Information Sharing', Journal of The Association for Information Science \& Technology, 65, 9, pp. 18501869, Business Source Premier, EBSCOhost, viewed 27 June 2018.

Kasemsap, K (2018) Encouraging Digital Literacy and ICT Competency in the Information Age (Chapter 196, pages 2253-2263) in Encyclopaedia of Information Science and Technology, Fourth Edition. DOI: 10.4018/978-1-5225-2255-3.ch196 Available at https://www.igi-global.com/chapter/encouraging-digital-literacy-and-ict-competency-in-theinformation-age/183938 accessed on 25 June 2018

Marsh, J, Brooks, G, Hughes, J Ritchie, L, Roberts, S and Wright, K (2005) Digital beginnings: Young children's use of popular culture, media and new technologies http://www.digitalbeginnings.shef.ac.uk/DigitalBeginningsReport.pdf accessed 20.4.18

Marsh, J. (2010) The relationship between home and school literacy practices, in D, Wyse, $R$ Andrews and J. Hoffman (Eds.) The International Handbook of English, Language and Literacy Teaching. London: Routledge, pp305-316

Merchant, G. (2012) Mobile practices in Everyday life: Popular digital technologies and school revisited. British Journal of Educational Technology. 43 (5) p. 770-782 
Midwife, S (2013), 'Stretch marks: results of an information journey', Essentially MIDIRS, 4, 1, pp. 46-49, CINAHL Plus with Full Text, EBSCOhost, viewed 27 June 2018.

Pegrum M. (2010) '“I link, therefore I am”: network literacy as a core digital literacy', Elearning and Digital Media, 2010, vol. 7/4 (pg. 346-54)

Google ScholarCrossRef

Pegrum M. Thomas M. (2011) 'Modified, multiplied and (re-)mixed: social media and digital literacies', Digital Education: Opportunities for Social Collaboration, 2011New York, NY Palgrave Macmillan

Picton, I and Teravainen, A (2017) Fake News and Critical Literacy An evidence review, National Literacy Trust accessed 31/02/18

Pontis, S, Blandford, A, Greifeneder, E, Attalla, H, \& Neal, D (2017), 'Keeping up to date: An academic researcher's information journey', Journal of The Association for Information Science \& Technology, 68, 1, pp. 22-35, Business Source Premier, EBSCOhost, viewed 15 June 2018.

Prensky, M (2001) "Digital Natives, Digital Immigrants Part 1", On the Horizon, Vol. 9 Issue: 5, pp.1-6, https://doi.org/10.1108/10748120110424816

Salisbury, F, \& Sheridan, L (2011), 'Mapping the journey: Developing an information literacy strategy as part of curriculum reform', Journal of Librarianship \& Information Science, 43, 3, pp. 185-193, Library, Information Science \& Technology Abstracts, EBSCOhost, viewed 27 June 2018.

Sharp, LA (2018), 'Collaborative Digital Literacy Practices among Adult Learners: Levels of Confidence and Perceptions of Importance', International Journal of Instruction, 11, 1, pp. 153-166, Education Research Complete, EBSCOhost, viewed 15 June 2018.

Tecce DeCarlo, M, Grant, A, Lee, V, \& Neuman, D (2018), 'Information and digital literacies in a kindergarten classroom: An I-LEARN case study', Early Childhood Education Journal, 46, 3, pp. 265-275, PsycINFO, EBSCOhost, viewed 15 June 2018.

Westrum, R (2014), 'The study of information flow: A personal journey', Safety Science, 67, pp. 58-63, Academic Search Premier, EBSCOhost, viewed 12 June 2018. 
Yousuf Ali, M (2016), 'South Asian Libraries Conference (SALC 2015), October 12-13, 2015 "Journey Through Print to Digital Information and Beyond"', International Information \& Library Review, 48, 1, pp. 67-70, Library, Information Science \& Technology Abstracts, EBSCOhost, viewed 27 June 2018. 